Dusan Jandacka - Daniela Durcanska - Dasa Kovalova*

\title{
CONCENTRATIONS OF TRAFFIC RELATED POLLUTANTS IN THE VICINITY OF DIFFERENT TYPES OF URBAN CROSSROADS
}

Pollution of the air by gases and particulate matter is a problem of everyday life. Particulate matter (PM) is one of the hazardous pollutants causing deterioration of the environment and thus quality of life of the population. Long-term exposure to effects of increased concentrations of gaseous pollutants can also cause deterioration of the environment and human health. Particulate matter and gases production by the road transport is a burning issue, particularly for larger urban areas. Many factors influence the air quality what determines its development and changes. Air pollution monitoring was focused on a possible change in the concentrations of pollutants after the change of the crossroad - three-arm crossroad to the roundabout. The subject of this paper is monitoring particulate matter $\left(P M_{P}, P M_{25}, P M_{10}\right)$ and gases (nitrogen oxides $\mathrm{NO}, \mathrm{NO}_{2}, \mathrm{NO}_{x}$ ) in the vicinity of crossroads in the urban area and an evaluation of fraction ratios $P M_{10} P M_{25}$ and $P M_{1}$ with regard to construction of crossroad, meteorological conditions and traffic volume. The roundabout has specific construction and routing traffic, what can influence on production and dispersion of traffic related emissions. The obtained results indicate a decrease in particulate matter concentrations at the roundabout over a three-arm crossroad and an increase in nitrogen oxides concentrations at the roundabout compared to the three-arm crossroad. According to the data obtained and analyzed, the PM ${ }_{10}$ particulate matter concentrations at the roundabout could be reduced by up to $50 \%$ over the three-arm crossroad.

Keywords: particulate matter, nitrogen oxides, roundabout, tree-arm crossroad, traffic volume

\section{Introduction}

The dispersion of pollutants in the atmosphere is a difficult process that is not subordinated only to spreading rates of different sources producing this pollution. Of course, the source of various pollutants is decisive for a number of substances that get into the ambient air. There are also other physical factors during the spreading of produced emissions, which determine the dispersion of pollutants into the surrounding environment. They are mainly meteorological parameters, the stability of the atmosphere and segmentation of the surrounding terrain [1-2]. Several studies have been devoted to the spread of pollution in the vicinity of roads, which have confirmed, to some extent, various levels of concentration of pollution considering the distance of the monitoring place from an anticipated source [3-4]. In general, it is confirmed that the greater distance from the road = lower the concentrations of pollutants. The layering of pollution in the vertical direction, has also not less important character, which shows a decrease with the higher terrain clearance [5-8]. The road traffic is one of the main sources of particulate matter, which produces particles not only in urban but in the rural environment, as well [9-11].

The concentrations of pollutants in the air may also be affected by the shape and construction of the road or crossroad (pavement, slope of the road, geometric shape of crossroad, traffic-light controlled crossroads ...) [12-16]. Crossroads are critical elements of road networks in terms of air quality impact, and their control type and geometric configuration can affect significantly vehicular emissions. At crossroads, the vehicles usually slow down and often stop, thus interrupting traffic flow in varying patterns. The main aim of one study was to compare the environmental performance of roundabouts and signal-controlled crossroads. Comparison of the crossroads was performed by a microsimulation model [17]. This paper discusses real air pollution in the vicinity of the two types of crossroads (three-arm crossroad - TAI and roundabout - ROA) and deals with the change of concentrations of pollutants (particulate matter - $\mathrm{PM}_{10}, \mathrm{PM}_{2.5}$, $\mathrm{PM}_{1}$ and nitrogen oxides - $\mathrm{NO}, \mathrm{NO}_{2}, \mathrm{NO}_{\mathrm{x}}$ ).

\section{Methodology of measurements}

Road transport produces various pollutants whose concentrations are the highest in the vicinity of roads or crossroads. Nowadays, the particulate matter of two fractions of $\mathrm{PM}_{10}$ and $\mathrm{PM}_{25}$ are the most mentioned. This study is focused on production of pollutants $\left(\mathrm{PM}_{10}, \mathrm{PM}_{25}, \mathrm{PM}_{1}, \mathrm{NO}, \mathrm{NO}_{2}, \mathrm{NO}_{\mathrm{x}}\right)$ from the road transport at the various crossroad types three-arm crossroad - TAI and roundabout - ROA.

\footnotetext{
* 'Dusan Jandacka, ${ }^{1}$ Daniela Durcanska, ${ }^{2}$ Dasa Kovalova

${ }^{1}$ Department of Highway Engineering, Faculty of Civil Engineering, University of Zilina, Slovakia

${ }^{2}$ Research Centre, University of Zilina, Slovakia

E-mail: dusan.jandacka@fstav.uniza.sk
} 


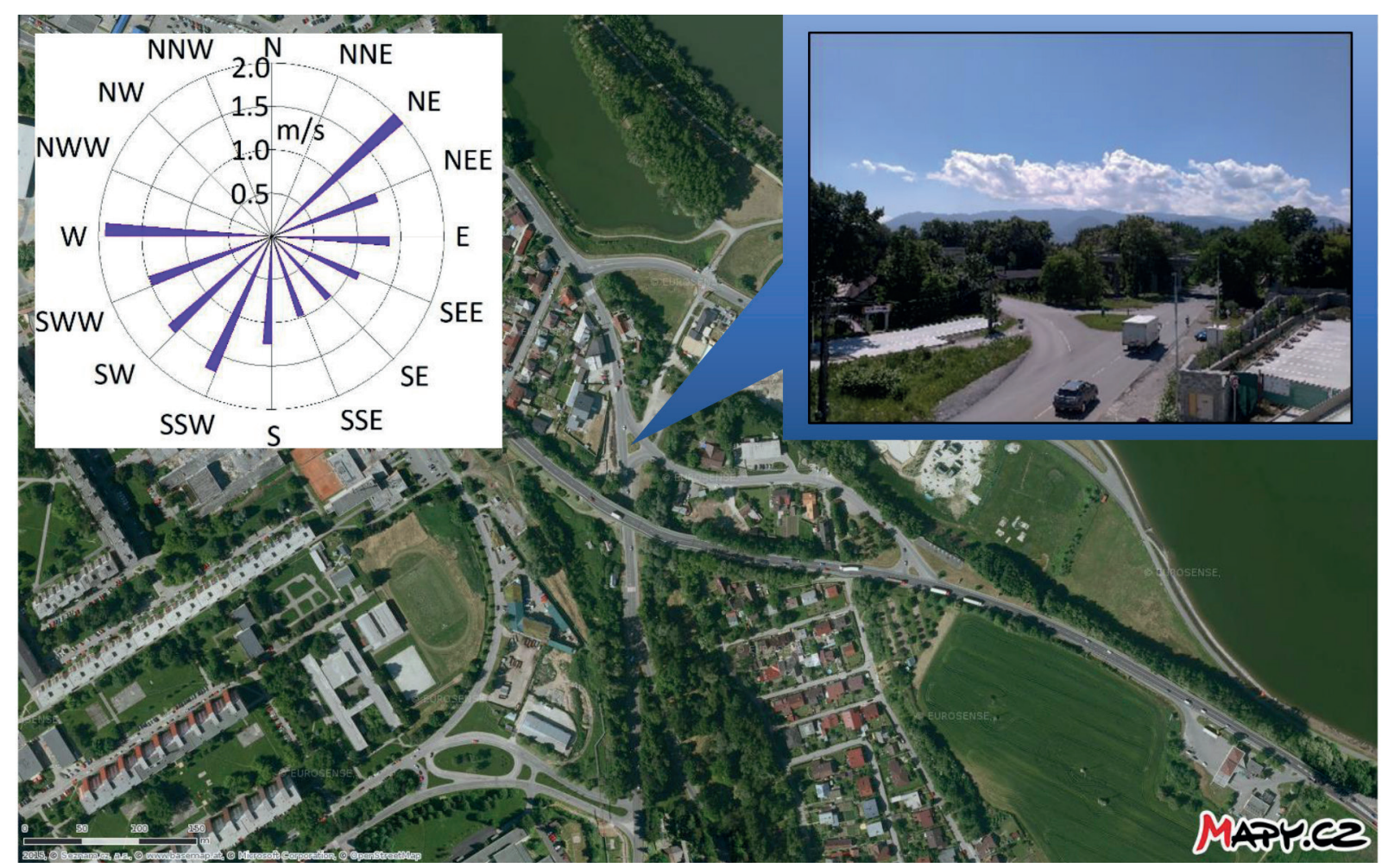

Figure 1 Three-arm crossroad before reconstruction, predominant winds during the measurement in the year 2016

\subsection{Study area}

The first measurement was realised at the TAI in the period from $25^{\text {th }}$ June till $1^{\text {st }}$ July 2016 (Pri celulozke Street and Rosinska Street) before the reconstruction. In that period, the reconstruction of this crossroad from tree-arm crossroad to the roundabout was planned. Existing original TAI was located at the point where industrial and recreational zone of the city of Zilina intersect with the built-up area of companies and facilities of recreation and services. It was located near the state road I/18 on the route Zilina-Martin-Kosice. It was a building of local significance that solves the reconstruction of the existing crossroad within the framework of the city development concept of the city of Zilina. In the case of an inconvenient traffic situation on the road $\mathrm{I} / 18$, this crossroad has become one of the strategic connections to the city of Zilina (especially from the direction of Martin). The existing crossroad was not a dangerous and accidental traffic locality in its original layout. However, the collision occurs within the encounter of pedestrians, cyclists and vehicles.

Concurrently, the construction and technical state of the intersected roads had a negative impact during the use of this traffic hub by both public and heavy vehicles transport (in the case of traffic diversion from the state road $\mathrm{I} / 18$ on the route Zilina-Martin) as connection of the city to the main road network. There were areas of parked cars in the solved locality of the existing original crossroad, where was an uncontrolled exit of these cars to the road traffic. The roads were being polluted from these unpaved areas and consequently the road dust was being re-suspended to air. Furthermore, the existing crossroad was the last traffic hub before the planned complete cross connection of the network of cycling and walking trails within the concept of city development, especially its relaxing and recreational areas (a dam named Vodne dielo Zilina).

The second measurement was realised at the ROA in the period from $24^{\text {th }}$ June till $30^{\text {th }}$ June 2016 after the reconstruction. The purpose of the reconstruction was to build a roundabout with a diameter of 36 meters in optimal location in terms of fluent and safe transport, as well as in terms of the impact of construction and operation on the population and the natural environment. The main purpose of the reconstruction of existing crossroad was to construct a high-quality and capacity convenient crossroad as a traffic hub for vehicles, but also for pedestrians and cyclists with connection to existing build-up area of companies, facilities and also with connection to residential areas and recreational zones.

Realization of this construction has increased the permeability and the capacity of the crossroad (change of the construction and technical state of the crossroad from three-arm crossroad to roundabout). By the construction of roundabout, the traffic flow has substantially increased during the occasional heavy vehicles transport, interaction between pedestrians (cyclists) and vehicles has also improved regarding to collisions, the cross connection hub of the network of cycling and walking trails has created from the Vlcince settlement (Trnova, Rosinky) in the next sequel to the dam Zilina. In addition, a coherent concept of connection of surrounding facilities, build-up area of companies and recreational zones was created. Respectively, new conditions were created for connecting to others zones.

In addition to this, there is a presumption of a change in the production of pollutants by the road transport, as the process of passing of vehicles through crossroad, vehicle speeds and pavement surfaces were changed. This is the subject of the described measurements, namely the change in the concentrations of pollutants for different types of crossroads. 


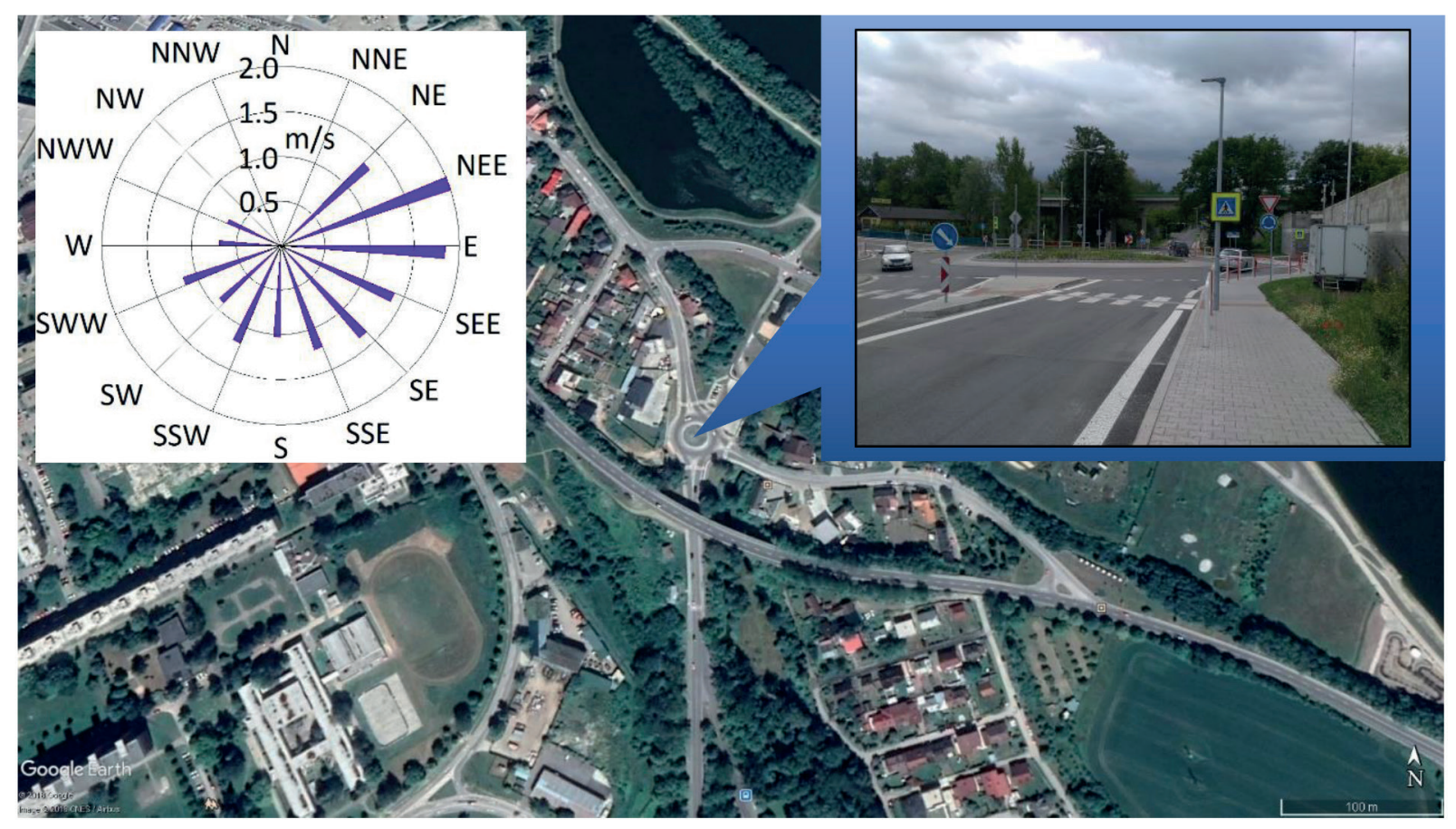

Figure 2 Roundabout after reconstruction, predominant winds during the measurement in the year 2017

The proposed roundabout consists of one traffic lane on a traffic circle width of 6.0 meters. The width of the center island is 3.0 meters for the passage of heavy and oversize vehicles. The widths of the entry and exit roads of the individual branches from roundabout are minimally $3.0 \mathrm{~m}$ alternatively minimally 5.50 meters between the rims. The curved bends at the entries to the intersection are in the range of 8 to 15 meters and at the exits are in the range of 8 to 14 meters depending on the importance of the traffic direction. For the passage of pedestrians and cyclists through the main branches of the intersection, the traffic islands with the necessary width at the point of passage were constructed.

Mobile Air Quality Monitoring Station of University of Zilina (MAQMS) was located next to the crossroads (three-arm crossroad and roundabout) at the same place in the years 2016 and 2017. The MAQMS has various measurement methods for the pollutant measuring. For the purposes of the $\mathrm{NO}_{\mathrm{x}}$ measurements, the standard chemi-luminescence method was used. On the other hand, for the particulate matter measurements, the optical method was used.

\subsection{Sample collection}

At the chosen measuring station, pollutants from the road transport, namely nitrogen oxides and particulate matter, were measured. Pollutants $\mathrm{NO}, \mathrm{NO}_{2}, \mathrm{NO}_{\mathrm{x}}, \mathrm{PM}_{10}, \mathrm{PM}_{2.5}$ and $\mathrm{PM}_{1}$ were measured and the following measurement methods were used at the measuring stations.

$\mathrm{NO}, \mathrm{NO}_{2}, \mathrm{NO}_{\mathrm{x}}$ - Standard chemi-luminescence method of measuring the concentration of nitrogen dioxide and nitrogen monoxide. Environment S.A Nitrogen Oxides Analyzer AC32M was used.

The sample is led into a pre-reaction chamber to be blended with ozone. The NO molecules contained in the gas are oxidized into $\mathrm{NO}_{2}$ before entering the reaction chamber. The signal thus measured without chemi-luminescence by the photomultiplier, may be considered as "zero air" measurement and used as a reference signal. Next the sample is directly led into the measurement chamber where NO oxidation by ozone is carried out. The signal measured by the photo-multiplier is proportional to the number of NO molecules contained in the sample. The sample flows through the converter oven, then it is blended with ozone inside the reaction chamber. The signal measured by the photo-multiplier is proportional to the number of the NO and $\mathrm{NO}_{2}$ (from the NO reduction) molecules contained in the sample. The ozone necessary for the chemi-luminescence reaction is generated by a discharge ozone generator.

$\mathrm{PM}_{10}, \mathrm{PM}_{2.5}$ and $\mathrm{PM}_{1}$ - Optical method. Fidas ${ }^{\circledR} 200$ fine dust aerosol spectrometer for simultaneous measurement from company Palas ${ }^{\circledR}$ was used.

The actual aerosol sensor is an optical aerosol spectrometer that determines the particle size using the Lorenz-Mie scattered light analysis of single particles. The single particles move through an optically differentiated measurement volume that is homogeneously illuminated with white light. Each particle generates a scattered light impulse that is detected at an angle of $85^{\circ}$ to $95^{\circ}$ degrees. The particle number is measured based on the number of scattered light impulses. The level of the scattered light impulse is a measure of the particle size diameter.

The meteorological parameters (temperature - TEMP, humidity - HUMI, wind velocity - WV and direction - WD, pressure - PRES) were measured as well as the traffic volume (Traff).

Concentrations of nitrogen oxides were measured as hourly concentrations in $\mathrm{ppb}$ and subsequently recalculated for standard conditions $\left(\mathrm{p}=101.325 \mathrm{kPa}\right.$ and $\mathrm{T}=293.15 \mathrm{~K}$ ) per unit $\mu \mathrm{g} / \mathrm{m}^{3}$. Concentrations of particulate matter were measured as hourly 


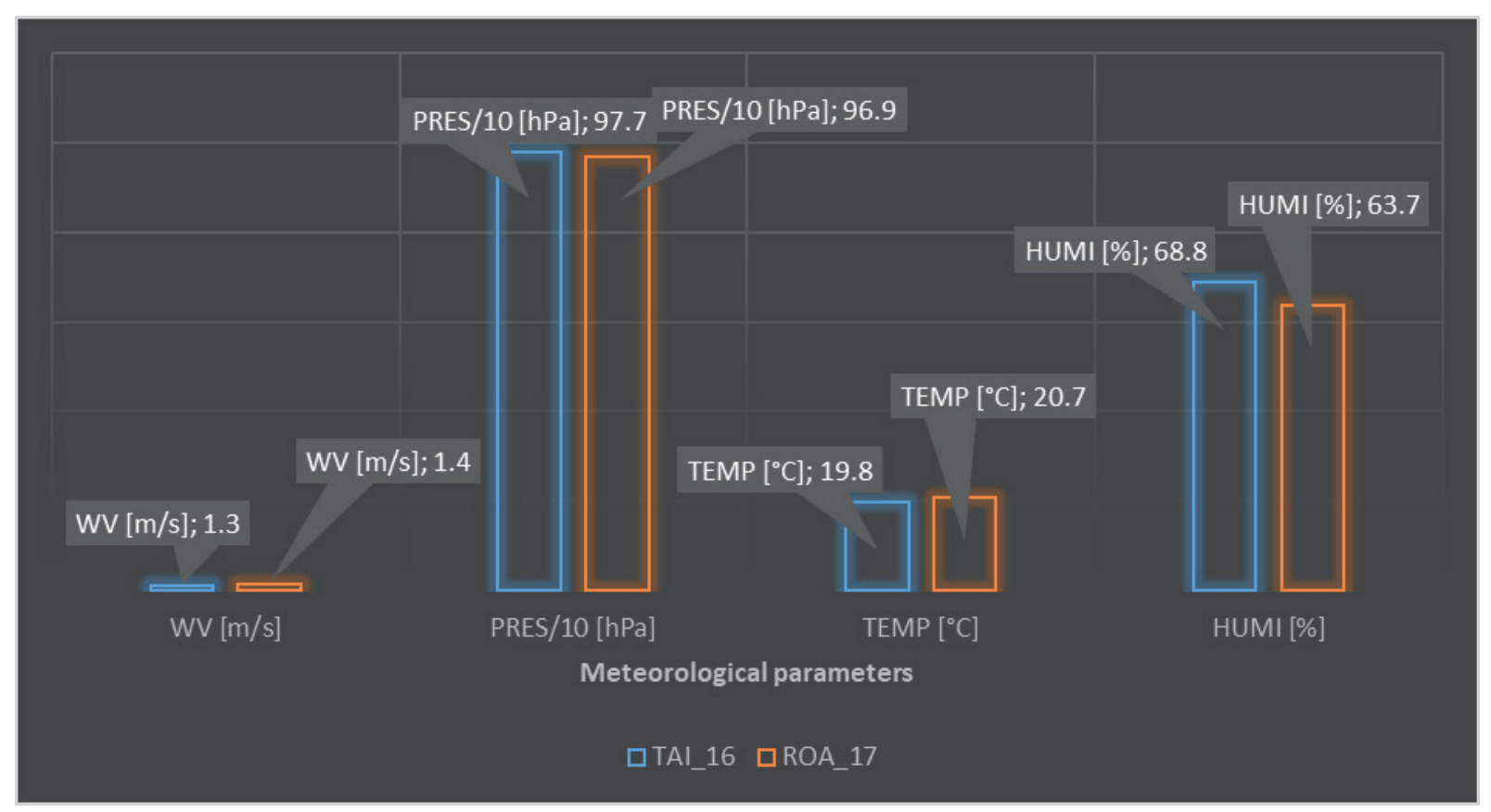

Figure 3 Meteorological parameters during both periods of measurement at the TAI in 2016 and ROA in 2017

concentrations in $\mu \mathrm{g} / \mathrm{m}^{3}$. Samples were captured during 7 days in 2016 (TAI) and 7 days in 2017 (ROA).

\section{Results and discussion}

The measurements of concentrations of pollutants were carried out near the TAI before the reconstruction and near the ROA after the reconstruction in the same place in the city of Zilina. The particulate matter concentrations of three fractions of $\mathrm{PM}_{10}, \mathrm{PM}_{2.5}$ and $\mathrm{PM}_{1}$ and the nitrogen oxides $\mathrm{NO}, \mathrm{NO}_{2}$ and $\mathrm{NO}_{\mathrm{x}}$ were sampled. Furthermore, the traffic volume was measured as the primary source of air pollution at the measuring place and meteorological parameters as secondary factors affecting concentrations of pollutants. All average values of pollutant concentrations were calculated from hourly values.

Both periods of measurements (TAI $-1^{\text {st }}$ period from $27^{\text {th }}$ June till $3^{\text {rd }}$ July 2016 and ROA $-2^{\text {nd }}$ period from $26^{\text {th }}$ June till $2^{\text {nd }}$ July 2017) were characterized by very similar meteorological conditions without rainfall. A slight change occurred in the temperature parameter (the temperature was higher by $0.9^{\circ} \mathrm{C}$ on average in the year 2017) and the relative humidity parameter (the relative humidity was lower by $5.1 \%$ on average in the year 2017) (Figure 3). The average wind speed during the measurement period (7 measuring days) was $1.3 \mathrm{~m} / \mathrm{s}$ in 2016 and $1.4 \mathrm{~m} / \mathrm{s}$ in 2017. The prevailing wind direction was predominantly from the road (crossroad) to the measuring station during both measurement periods (Figures 1,2).

The traffic volume was evaluated in the unit vehicles per 24 hours in individual measuring days. The measurements were set up to measure pollutants the whole week including five working days and two weekend days. During the working days and weekend days, a higher traffic volume was observed at the ROA in 2017 in comparison to observed traffic volume at the TAI in 2016 (Figure 4). The average traffic volume for the whole measurement period increased by $8.1 \%$ at the ROA in 2017 (15 036 vehicles/24 hours) compared to average traffic volume at the TAI in 2016 (13 910 vehicles/24 hours). Entry road "Vlcince" has been the entry to the crossroad with the highest average traffic volume at both types of crossroads. The average traffic volume at that entry at the original TAI in 2016 was 5946 vehicles per 24 hours and at the ROA in 2017 the average traffic volume was 6655 vehicles per 24 hours (Figure 5). From the perspective of the course of traffic volume, significant annual increase has been shown in 2017 compared to 2016. In terms of emission production, it is questionable how the reconstruction of the crossroad may contribute to a change of concentrations of pollutants.

The road transport produces various pollutants, especially particulate matter and nitrogen oxides. The observed mean 24-hour concentrations of nitrogen oxides were higher at the ROA in 2017 than at the TAI in 2016. The Nitrogen oxide concentrations were lower only on Wednesday and Thursday in 2017 as in 2016 (Figure 6). At the ROA in 2017, the average concentrations during the whole measurement period increased by $86 \%$ for $\mathrm{NO}, 116 \%$ for $\mathrm{NO}_{2}$ and $105 \%$ for $\mathrm{NO}_{\mathrm{x}}$ compared to the TAI in 2016 (Figure 7). What regards the traffic volume, the increase has been observed which could contribute to higher concentrations of nitrogen oxides. The measurement periods in 2016 and 2017 were almost similar in terms of meteorological parameters because of their minimal changes. The cause of such a significant change in the concentrations of nitrogen oxides appears primarily due to the change of shape of the solved crossroad. At the original TAI before reconstruction, the vehicle speeds were higher than at the ROA on the main route Vlcince Kosicka. Vehicles did not slowdown in this direction and crossed the TAI with maximum speed. Dispersion of gaseous emissions of nitrogen oxides was more intense and did not accumulate in the crossroad area. Also, there was no need for deceleration and acceleration during the crossing of the crossroad, which leads to the higher engine load and higher production of emissions. 


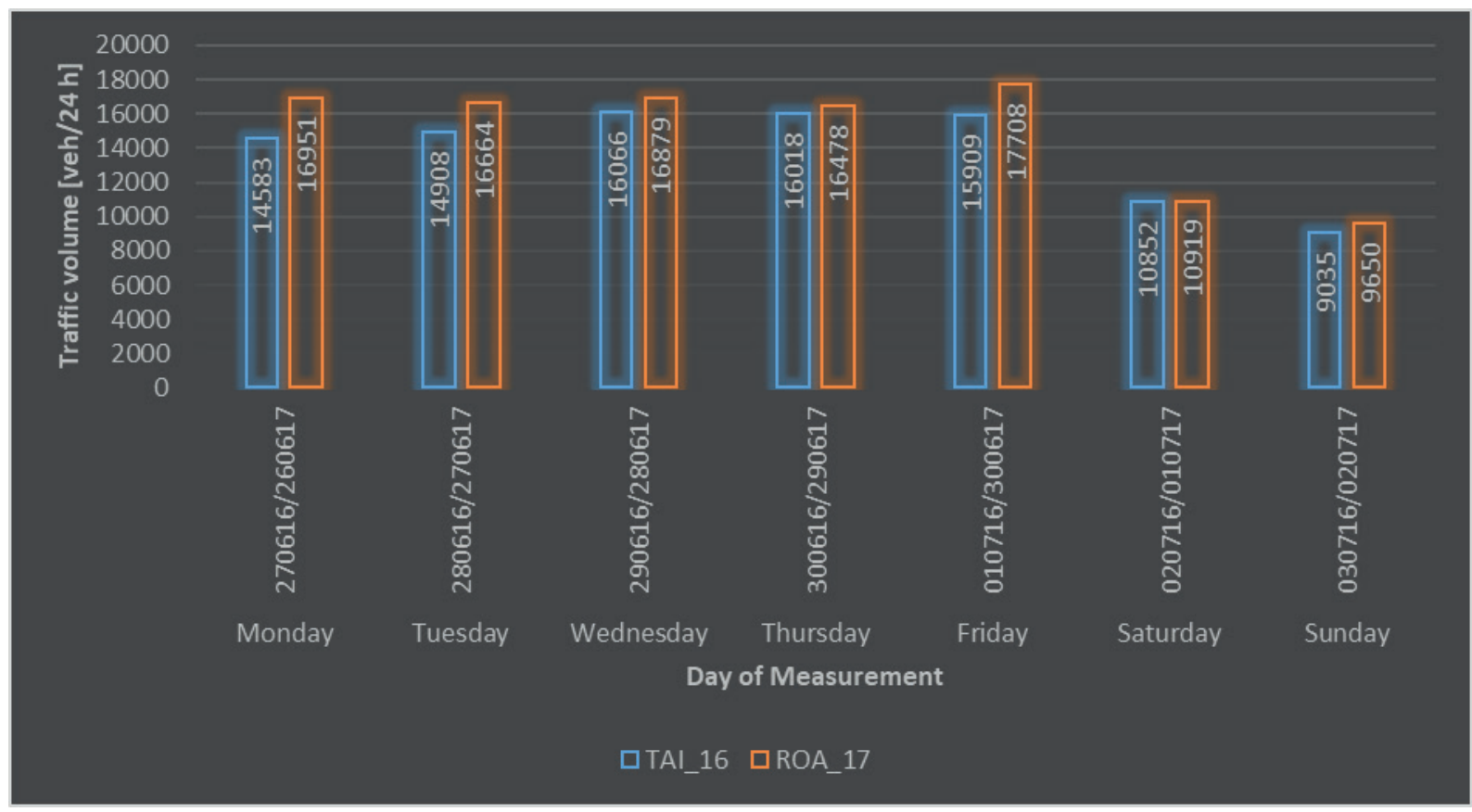

Figure 4 Traffic volume during both periods of measurement at the TAI in 2016 and ROA in 2017

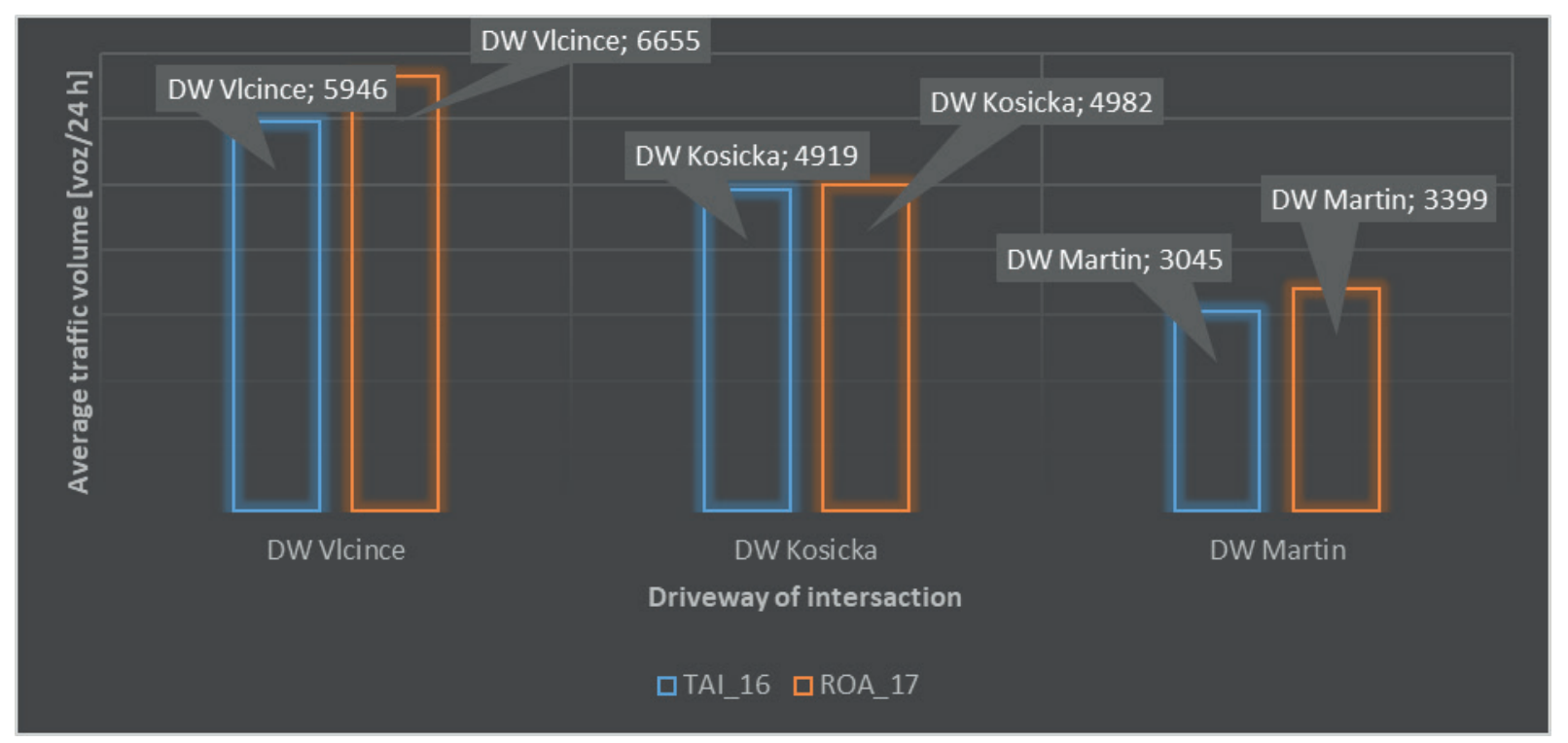

Figure 5 Average traffic volume regarding to the direction of crossroad branch at the TAI in 2016 and ROA in 2017

At the new ROA, vehicles have to slowdown ahead of the traffic circle and prefer the vehicles on the traffic circle. At the same time, vehicle speeds are much lower. Due to the more demanding engine operation during the deceleration and acceleration, the emissions of nitrogen oxides are produced to a greater extent. In addition, the lower speeds also cause that nitrogen oxide emissions are longer remaining in the area around the crossroad.

On the other hand, a decrease in particulate matter concentrations at the ROA in 2017 was observed compared to the TAI in 2016 (Figure 8). The average decrease in particulate matter concentrations during the whole measurement period at the ROA was $35 \%$ for $\mathrm{PM}_{10}, 38 \%$ for $\mathrm{PM}_{2.5}$ and $41 \%$ for $\mathrm{PM}_{1}$ (Figure 9 ). Due to the fact that the traffic volume in 2017 has increased compared to 2016, it is necessary to look for the causes of the reduction in particulate matter concentrations in the secondary factors affecting the PM concentrations.

The coarse fraction $\mathrm{PM}_{2.5-10}$ comprises more than $50 \%$ of the fraction $\mathrm{PM}_{10}$. The particulate matter distribution found from measurements in 2016 and 2017 is very similar (Figure 10). The change can be seen above all in the actual concentrations of the particulate matter. In the summer when the measurements were carried out, the coarse fraction of particulate matter has a higher representation in the $\mathrm{PM}_{10}$ fraction. The coarse fraction $\mathrm{PM}_{2.5-10}$ comes mainly from the resuspension of road dust and the resuspension of particulates from the surfaces around the road. These particulate matters are formed from abrasion of vehicle parts, road surfaces, but also from the earth's crust, which are subsequently deposited on the road surface. By the passing of vehicles through crossroad, the particulate matters are back 


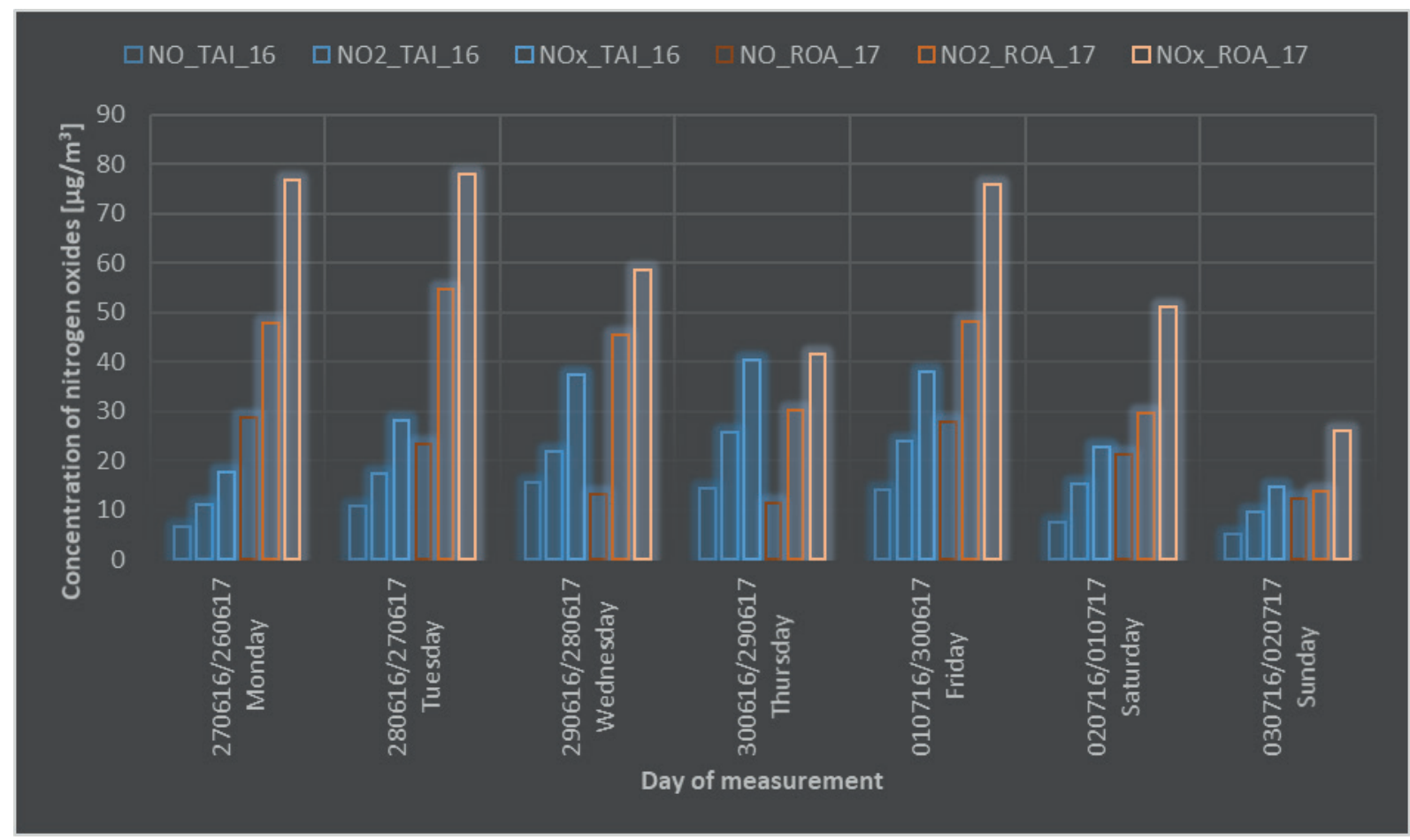

Figure 6 Concentrations of nitrogen oxides during both periods of measurement at the TAI in 2016 and ROA in 2017

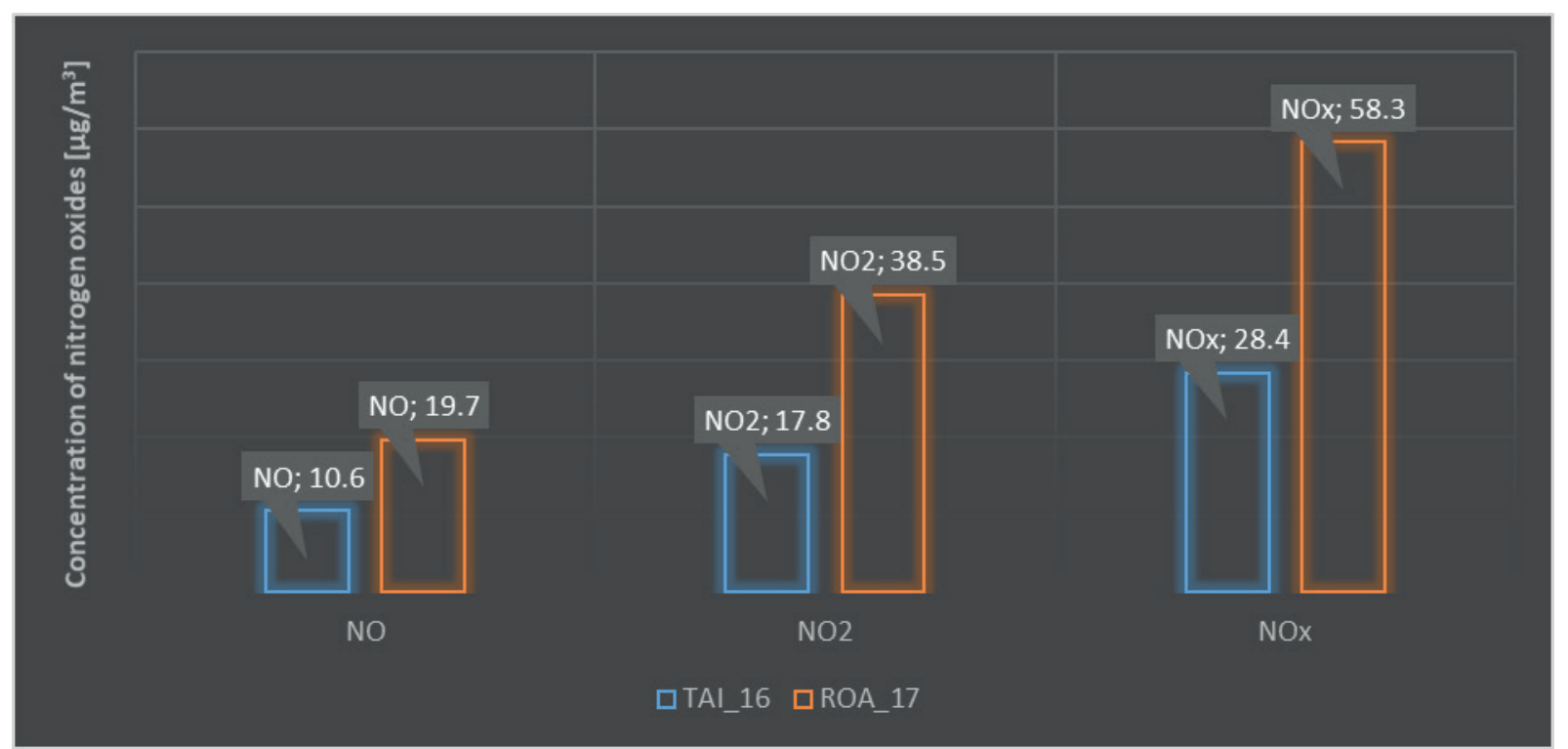

Figure 7 Average concentrations of nitrogen oxides (NO, NO ${ }_{2}$ and $\mathrm{NO}_{x}$ ) for the whole period of measurements at the TAI in 2016 and ROA in 2017

re-suspended into the air. At the TAI in 2016, the passing of vehicles in the main direction was faster (higher vehicle speed) so the particulates were re-suspended more intensely from the road surface into the air. Concurrently, the road surface before reconstruction was degraded and there were more unpaved areas in the vicinity of the crossroad. From these unpaved areas, the road surface was more polluted. At the ROA in 2017, the crossing vehicle speeds were lower, causing the resuspension of particulate matters from the road surface not to be so active. At the same time, the paved areas were built around the crossroad (pavements, parking areas). From meteorological parameters, the wind velocity and atmospheric precipitation have the most significant influence on particle matter concentrations. The wind speed did not change significantly in 2017 compared to 2016 and the precipitation was not observed during both measurement periods. There is probably no change of concentrations of particulate matter in terms of detected changes of meteorological parameters.

The impact of traffic volume on concentrations of pollutants can be clearly seen by comparing working days and weekend days. During the working days, the traffic volume and concentration of pollutants have always been higher. The values of decreases in concentrations of pollutants during the weekend days can be seen in Table 1.

From the point of view of the road transport impact on the environment, lower concentrations of particulate matter were recorded near the ROA than near the TAI. This fact was found despite the higher traffic volume at the ROA than on the TAI. If the minimum or no change of meteorological parameters in 
Table 1 The average concentrations of pollutants during the workdays and weekend

\begin{tabular}{|c|c|c|c|c|c|c|c|c|c|c|}
\hline \multirow{2}{*}{$\begin{array}{c}\text { Intersection type/ } \\
\text { Year }\end{array}$} & \multirow[t]{2}{*}{ Days } & NO & $\mathrm{NO}_{2}$ & $\mathrm{NO}_{\mathrm{x}}$ & $\mathrm{PM}_{10}$ & $\mathrm{PM}_{2.5}$ & $\mathrm{PM}_{1}$ & $\mathrm{PM}_{2.5-10}$ & $\mathrm{PM}_{1-2.5}$ & Traffic volume \\
\hline & & \multicolumn{8}{|c|}{$\mu \mathrm{g} / \mathrm{m}^{3}$} & veh $/ 24 \mathrm{~h}$ \\
\hline \multirow[t]{2}{*}{ TAI/2016 } & Workdays & 12.3 & 20.0 & 32.3 & 25.2 & 11.5 & 9.2 & 13.7 & 2.3 & 15497 \\
\hline & Weekend & 6.4 & 12.4 & 18.8 & 16.7 & 9.4 & 7.8 & 7.3 & 1.7 & 9944 \\
\hline \multicolumn{2}{|c|}{ Change of value over the weekend } & -5.9 & -7.6 & -13.5 & -8.5 & -2.1 & -1.5 & -6.4 & -0.7 & -5553 \\
\hline \multirow[t]{2}{*}{$\mathrm{ROA} / 2017$} & Workdays & 20.9 & 45.3 & 66.1 & 16.7 & 7.7 & 5.9 & 9.0 & 1.8 & 16936 \\
\hline & Weekend & 16.9 & 21.7 & 38.6 & 10.0 & 4.5 & 3.3 & 5.5 & 1.2 & 10285 \\
\hline \multicolumn{2}{|c|}{ Change of value over the weekend } & -4.0 & -23.6 & -27.6 & -6.7 & -3.2 & -2.6 & -3.5 & -0.6 & -6652 \\
\hline
\end{tabular}

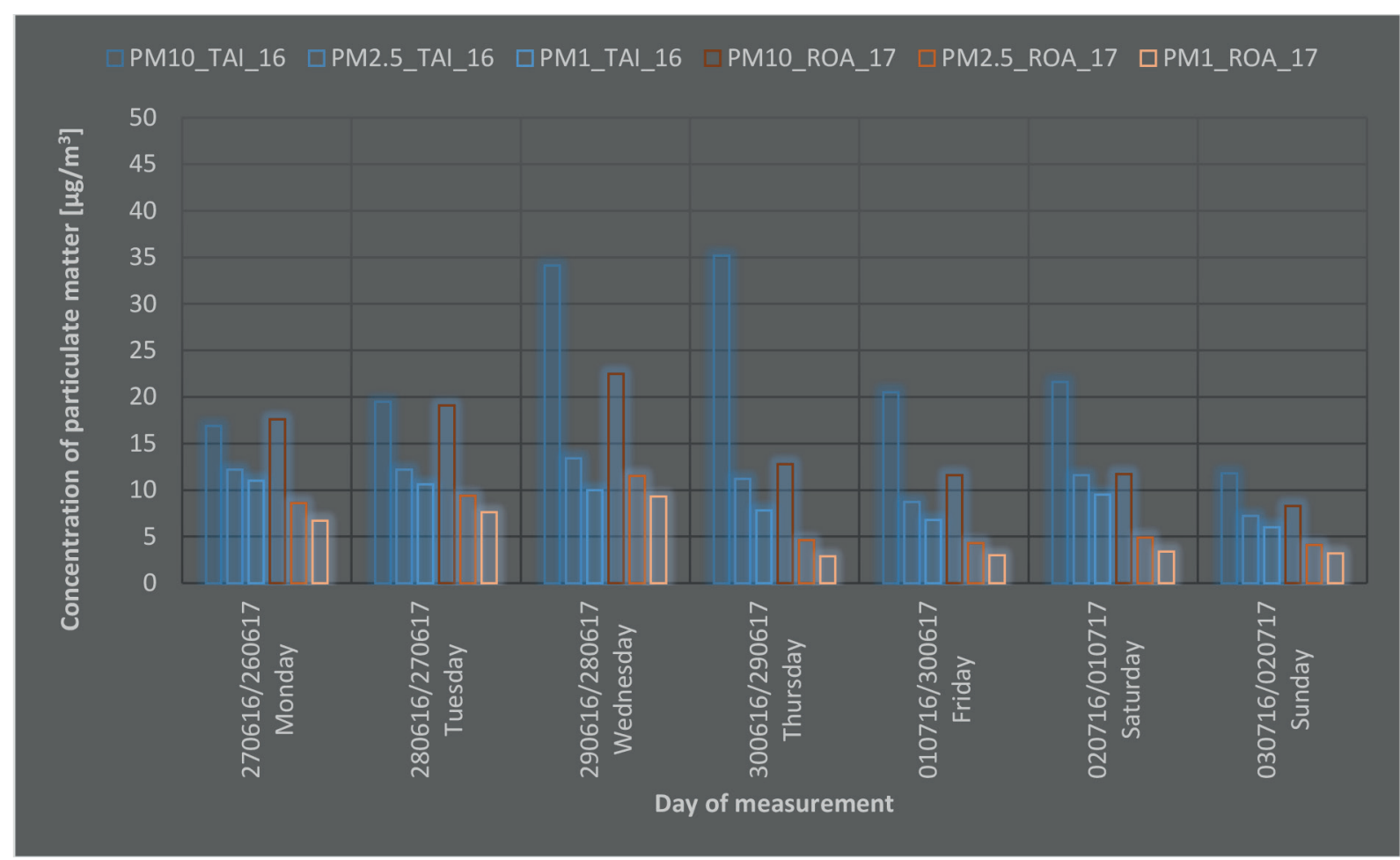

Figure 8 Concentrations of particulate matter during both periods of measurement at the TAI in 2016 and ROA in 2017

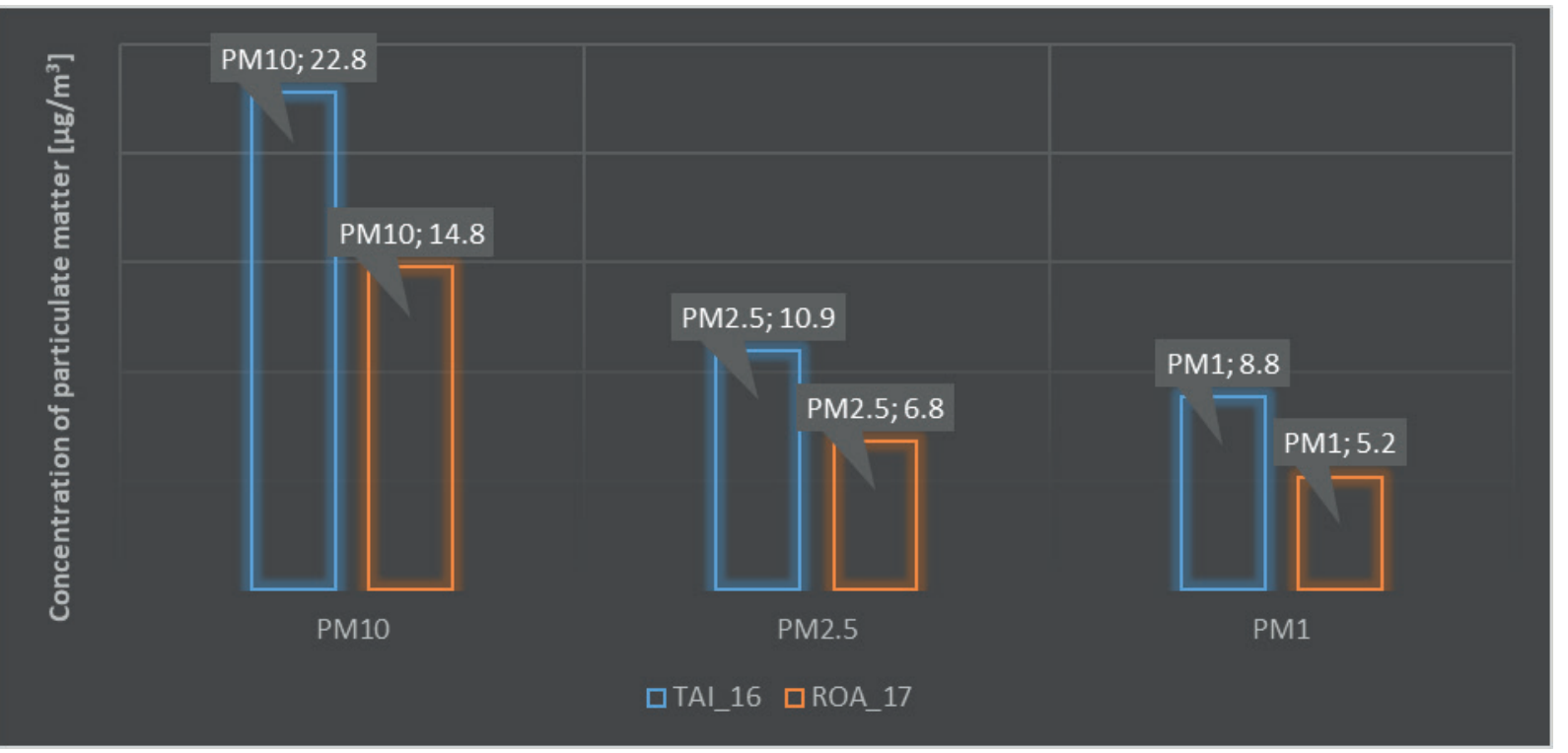

Figure 9 Average concentrations of particulate matter $\left(P M_{10}, P M_{2,5}\right.$, and $\left.P M_{1}\right)$ for the whole period of measurements at the TAI in 2016 and ROA in 2017 

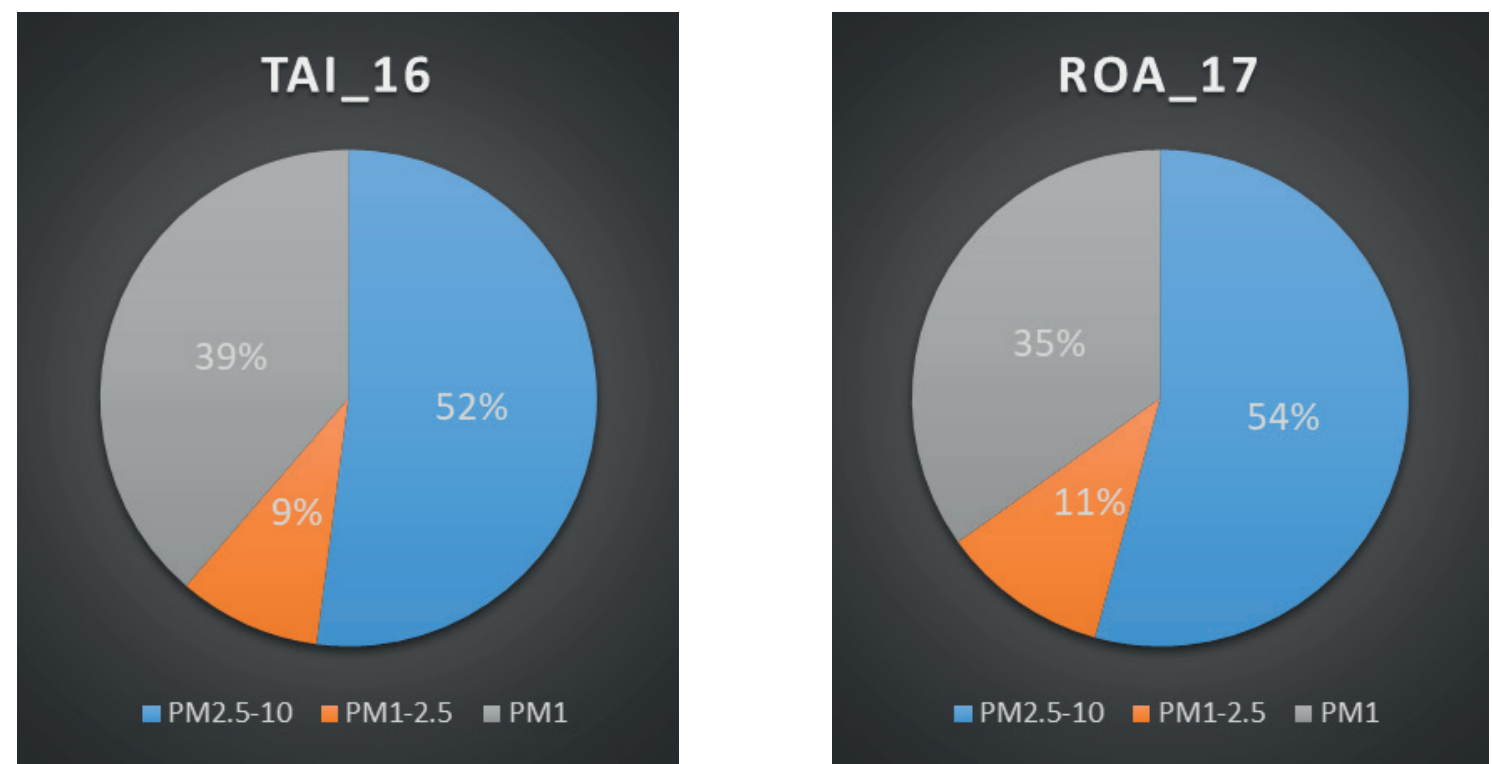

Figure 10 Distribution of the PM fractions in the total PM ${ }_{10}$ fraction measurements at the TAI in 2016 and ROA in 2017

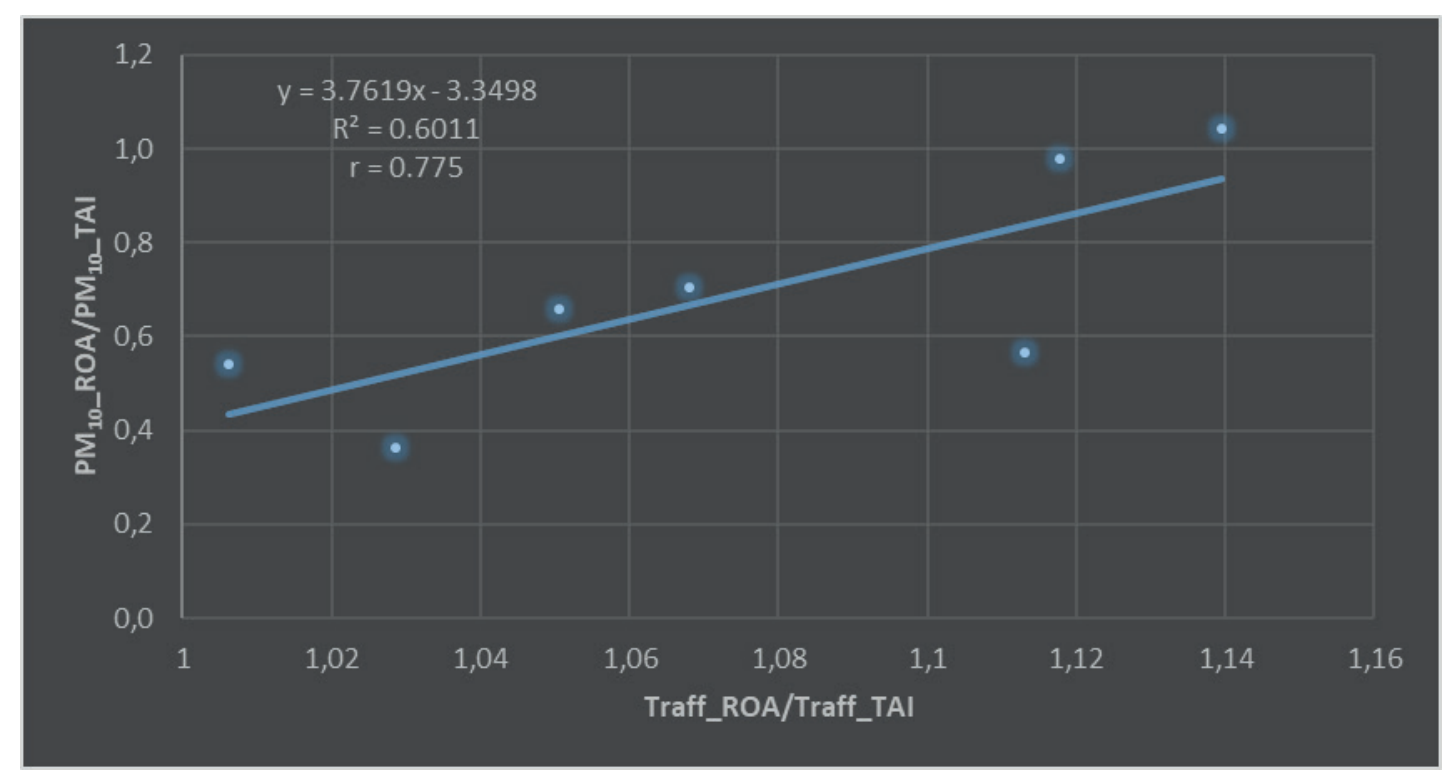

Figure 11 Change in the $P M_{10}$ particulate matter concentrations at the ROA compared to the TAI due to the change in traffic volume

the atmosphere is taken into account a correlation relationship between the traffic volume change (Traff_ROA / Traff_TAI) and the particulate matter $\mathrm{PM}_{10}$ concentration change $\left(\mathrm{PM}_{10-} \mathrm{ROA}\right.$ / $\mathrm{PM}_{10-} \mathrm{TAI}$ ) can be created. By performing a linear regression analysis, the computational matrix consisted of an independent variable traffic volume ratio - Traff_ROA / Traff_TAI and the dependent variable particulate matter $\mathrm{PM}_{10}$ concentration ratio $\mathrm{PM}_{10-}$ ROA / $\mathrm{PM}_{10-}$ TAI. The analysis showed (using the measured data) that if the traffic volume at the ROA did not increase over the TAI, a drop of the $\mathrm{PM}_{10}$ particulate matter concentrations could reach up to $60 \%$. At the same time, the largest change in the traffic volume +2034 vehicles / $24 \mathrm{~h}$ at the ROA compared to the TAI did not lead to a decrease in the $\mathrm{PM}_{10}$ particulate matter concentrations (Figure 11).

\section{Conclusions}

The changes in concentrations of pollutants may be influenced by different environmental factors. On one hand, there may be primary sources of pollutants, such as the road transport, industry, agriculture, local heating, etc., and on the other hand there are secondary factors such as meteorological parameters, shape and segmentation of landscape relief, various artificial barriers in the country - buildings, noise barriers, etc.

In this contribution, it was dealt with possible change in concentrations of pollutants - particulate matter of three fractions of $\mathrm{PM}_{10}, \mathrm{PM}_{2.5}$ and $\mathrm{PM}_{1}$ and nitrogen oxides $\mathrm{NO}, \mathrm{NO}_{2}$ and $\mathrm{NO}_{\mathrm{x}}$ from the road transport in terms of different types of crossroads. In 2016, pollutants were measured at the original three-arm crossroad - TAI, which has been then reconstructed to the new roundabout - ROA. In 2017, the measurements of pollutants were performed at the new ROA. Significant change occurred 
in the shape of the crossroad, modification of its surroundings, character of the vehicle passing through the crossroad (vehicle speed, maneuvering). The traffic volume increased by $8.1 \%$ at the ROA on average compared to the TAI during the whole measuring period ( 7 days). The meteorological parameters did not change significantly and can be considered very similar for both measurement periods. However, the concentrations of nitrogen oxides and particulate matter have showed substantial change. An increase of concentrations of nitrogen oxides was found, namely by $86 \%$ for NO, by $116 \%$ for $\mathrm{NO}_{2}$ and by $105 \%$ for $\mathrm{NO}_{\mathrm{x}}$ at the ROA compared to the TAI. The increase of nitrogen oxides was mainly caused by the change in the shape of the crossroad and thus the character of the road traffic. Vehicles crossed the ROA at a lower speed, increased engine load in acceleration and deceleration, which caused a higher accumulation of nitrogen oxides and also lower dispersion near the crossroad. With regard to the particulate matter concentrations at the roundabout, the decrease was found. Concentrations of the $\mathrm{PM}_{10}$ decreased by $35 \%, \mathrm{PM}_{2.5}$ by $38 \%$, and $\mathrm{PM}_{1}$ by $41 \%$. Therefore, the change of the crossroad shape affected also the PM concentrations. In addition, the process of vehicles passing through the ROA (lower speeds, lower air swirl) caused a reduction in the re-suspended road dust, especially the coarse fraction of the $\mathrm{PM}_{2.5-10}$ particulates. Analysis of data showed that if the traffic volume at the ROA did not increase over the TAI, a drop of $\mathrm{PM}_{10}$ particulate matter concentrations could reach up to $60 \%$.

From the conducted research it can be concluded that the modification of the crossroad can affect the concentrations of pollutants. In this case, the concentrations of nitrogen oxides increased and the concentrations of particulate matter decreased.

\section{Acknowledgements}

The paper originated as being supported by means of a grant VEGA $1 / 0537 / 17$ «The influence of pavement surface morphology on pavement serviceability and emissions production».

\section{References}

[1] IWARI. S., et al. Variability in atmospheric particulates and meteorological effects on their mass concentrations over Delhi, India. Atmospheric Research [online]. 2014, 145-146, p. $45-56$ [accessed 2014-04-30]. ISSN 0169-8095. Available from: https://doi. org/10.1016/j.atmosres.2014.03.027

[2] TECER, L. H. Comparison and seasonal evaluation of the rural and urban ambient $\mathrm{PM}_{2.5}$ and $\mathrm{PM}_{10}$ mass concentrations based on meteorological parameters. In $13^{\text {th }}$ International Multidisciplinary Scientific GeoConference Surveying Geology and Mining Ecology Management, SGEM 2013: proceedings [online]. Section Air Pollution and Climate Change. Sofia, Bulgaria: STEF92 Technology Ltd., 2013. ISBN 978-619-7105-03-2, ISSN 1314-2704, p. 593-600. Available from: https://doi.org/10.5593/SGEM2013/ BD4/S19.011

[3] JUNG, K. H., ARTIGAS, F., SHIN J. Y. Seasonal gradient patterns of polycyclic aromatic hydrocarbons and PM concentrations near a highway. Atmosphere [online]. 2011, 2(3), p. 533-552. ISSN 2073-4433. Available from: https://doi.org/10.3390/ atmos 2030533

[4] SHARMA, A., MASSEY, D. D., TANEJA, A. Horizontal gradients of traffic related air pollutants near a major highways in Agra, India. Indian Journal of Radio a Space Physics [online]. 2009, 38, p. 338-346. ISSN 0367-8393/eISSN 0367-8393. Available from: http://nopr.niscair.res.in/bitstream/123456789/6901/1/IJRSP\%2038(6)\%20338-346.pdf

[5] HITCHNINS, J., et al. Concentrations of submicrometre particles from vehicle near a major roads. Atmospheric Environment [online]. 2000, 34(1), p. 51-59. ISSN 1352-2310. Available from: https://doi.org/10.1016/S1352-2310(99)00304-0

[6] MORAWSKA, L., et al. A study of the horizontal and vertical profile of submicrometer particles in relation to a busy road. Atmospheric Environment [online]. 1999, 33(8), p. 1261-1274. ISSN 1352-2310. Available from: https://doi.org/10.1016/S13522310(98)00266-0

[7] ROORDA-KNAPE, M. C., et al. Air pollution from traffic in city districts near major motorways. Atmospheric Environment [online]. 1998, 32(11), p. 1921-1930. ISSN 1352-2310. Available from: https://doi.org/10.1016/S1352-2310(97)00496-2

[8] WU, Y., et al. Vertical and horizontal profiles of airborne particulate matter near major roads in Macao. China. Atmospheric Environment [online]. 2002, 36, p. 4907-4918. ISSN 1352-2310. Available from: https://doi.org/10.1016/S1352-2310(02)00467-3

[9] JANDACKA, D. Contributory assessment of creation of $\mathrm{PM}_{10}$ as impacted by vehicular traffic based on the presence of heavy metals. Communications - Scientific Letters of the University of Zilina [online]. 2013, 15(3), p. 96-101. ISSN 1335-4205/eISSN 25857878. Available from: http://komunikacie.uniza.sk/index.php/communications/article/view/695

[10] JANDACKA, D., DURCANSKA, D., BUJDOS, M. The contribution of road traffic to particulate matter and metals in air pollution in the vicinity of an urban road. Transportation Research Part D: Transport and Environment [online]. 2017, 50, p. 397-408. ISSN 1361-9209/eISSN 1879-2340. Available from: https://doi.org/10.1016/j.trd.2016.11.024

[11] PANT, P., HARRISON, R. M. Estimation of the contribution of road traffic emissions to particulate matter concentrations from field measurements: A review. Atmospheric Environment [online]. 2013, 77, p. 78-97. ISSN 1352-2310. Available from: https://doi. org/ 10.1016/j.atmosenv.2013.04.028 
[12] FULLOVA, D., et al. Mass distribution of particulate matter produced during abrasion of asphalt mixtures in laboratory. Communications - Scientific Letters of the University of Zilina [online]. 2016, 18(4), p. 37-43. ISSN 1335-4205/eISSN 2585-7878. Available from: http://komunikacie.uniza.sk/index.php/communications/article/view/286

[13] DURCANSKA, D. Analysis of particulate matter composition. Communications - Scientific Letters of the University of Zilina [online]. 2010, 12(3A), p. 17-22. ISSN 1335-4205/eISSN 2585-7878. Available from: http://komunikacie.uniza.sk/index.php/ communications/article/view/939

[14] REMISOVA, E., DECKY, M., KOVAC, M. The influence of the asphalt mixture composition on the pavement surface texture and noise emissions production. In: 14th International multidisciplinary scientific conference SGEM 2014, Geoconference on Energy and clean Technologies: proceedings [online]. Section Air pollution and Climate change. Albena, Bulgaria, 2014, Vol. 2, Book 4, ISBN 978-619-7105-16-2/ISSN 1314-2704, p. 583-590. Available from: https://doi.org/10.5593/SGEM2014/B42/S19.077

[15] TROJANOVA, M., DECKY, M., REMISOVA, E. The implication of climatic changes to asphalt pavement design. In: 24th Russian-Polish-Slovak Seminar on Theoretical Foundation of Civil Engineering, TFoCE 2015: proceedings [online]. Samara, Russian Federation, 2015. Vol. 111. ISSN 1877-7058, p. 770-776. Available from: https://doi.org/10.1016/j.proeng.2015.07.144

[16] KOCIANOVA, A., DRLICIAK, M., PITLOVA, E. Influence of roundabout capacity enhancement on emission production. IOP Conference Series: Materials Science and Engineering [online]. 2017, 236, 012035. ISSN 17578981. Available from: https://doi. org/10.1088/1757-899X/236/1/012035

[17] GASTALDI, M., et al. Evaluation of air pollution impacts of a signal control to roundabout conversion using microsimulation. Trans. Res. Procedia [online]. 2014, 3, p. 1031-1040. ISSN 2352-1465. Available from: https://doi.org/10.1016/j.trpro.2014.10.083 